www.jmscr.igmpublication.org

Impact Factor (SJIF): 6.379

Index Copernicus Value: 79.54

ISSN (e)-2347-176x ISSN (p) 2455-0450

crossrefDOI: https://dx.doi.org/10.18535/jmscr/v6i10.119

\title{
24 Hour Ambulatory Blood Pressure Monitoring in Normotensive Individuals from our Population
}

Authors

Vikas Agrawal, Aviraj Choudhary, Geetha Subramanian

IMS, BHU, India

\begin{abstract}
Aim of study: To study the BP levels and diurnal pattern on 24 hrs ambulatory monitoring in normotensive individuals from our population.

Material and Methods: 90 normotensive individuals of either sex with BP persistently $<140 / 90$ mmHg (DBP-Korotkoff Phase V) not taking any antihypertensive medication were studied. All cases were subjected to $24 \mathrm{hr}$ ambulatory blood pressure monitoring.

Results: The mean nighttime SBP and DBP were significantly lower than the mean daytime SBP and DBP. The mean nocturnal fall in SBP and DBP was $-8.8 \pm 5.27$ and $7.9 \pm 3.49 \mathrm{~mm} \mathrm{Hg}$ respectively. In $94 \%$ nocturnal dipping was observed. Nocturnal dipping was less in persons aged > 40 years. No significant difference in nocturnal dipping between males and females was observed.

Conclusion: The 24 hour BP profile in our cases was similar to the western population. It seems that the criteria for elevated BP on ABPM adopted in the present guidelines are suitable for our population. Twenty-four hour ambulatory BP monitoring was well tolerated by our cases and there was no major problem.

Keywords: Blood pressure, ambulatory monitoring.
\end{abstract}

\section{Introduction}

Non invasive ambulatory blood pressure monitoring (ABPM) is finding increasing application in the management of hypertension. ABPM offers several advantages over conventional casual or office BP recording ${ }^{[1]}$.

The criteria for normality and abnormality on ABPM have been largely established by studies undertaken in western population $^{(2-6)}$. It is known that there are ethnic and racial differences in the profile of hypertension ${ }^{(7)}$. There is little data on
ABPM from our own population. Hence in the present study we have studied the 24 hour BP profile by ABPM in our normotensive subjects.

\section{Material and Methods}

We studied 90 normotensive cases of either sex. The BP in all the cases was in the normal range ( $<140 / 90 \mathrm{~mm}$ of Hg, DBP-Korotkoff Phase V) on at least 3 previous occasions at least a week apart each. Cases with diabetes mellitus, renal disease, valvular heart disease, heart failure, endocrinal 
disorders, diarrhoea were excluded. No case was on any antihypertensive drug or taking any medication, which could affect BP. None of the cases smoked or consumed alcohol. Thorough general and systemic examination was done in all cases.

Ambulatory blood pressure monitoring for 24 hours was carried out in all the cases. The BP monitoring was done with Hyperwatch 2.2 equipment, which employs oscillometric method. The device was applied in the morning at about 9:30 AM and continued for the next 24 hours. It was programmed to inflate at every 30 minutes during the day and 45 minutes during the night. The detailed methodology of ABPM is described elsewhere ${ }^{[1,8]}$ and was followed here. The active time was from 6AM to $10 \mathrm{PM}$ and resting time was from $10 \mathrm{PM}$ to $6 \mathrm{AM}$. The blood pressure readings were stored in the unit, which were later transferred to a computer and analyzed. A diary was given to the patients to maintain a record of the activities during the 24 hours. Threshold values for calculating BP load adopted were - daytime BP >140/90 and nighttime $\mathrm{BP}>125 / 75 \mathrm{~mm} \mathrm{Hg}^{[1,8]}$. Statistical analysis was done with the student $t$ test.

\section{Results}

The mean age of our subjects was 32.6 \pm 8.91 years (range 22-55 years); 73\% $(\mathrm{n}=66)$ males and $27 \% \quad(n=24)$ females. Forty-seven percent were in the age group 20-29 years, 23\% in 30-39 years, $17 \%$ in $40-49$ years and $13 \%$ in > 50 years age. The mean weight was $53.73 \pm 8.49$ $\mathrm{kg}$ and height $158 \pm 7.86 \mathrm{~cm}$.

\section{Mean Blood Pressure Values on ABPM}

The mean daytime, nighttime and 24 hour BP in our subjects are shown in Table -1. The mean nighttime BP both systolic and diastolic were significantly lower than the mean day time BP $(\mathrm{P}<0.001)$.

\section{Comparison of Simultaneous Casual BP Determined By ABPM Device}

The comparison between simultaneous casual BP taken before the start of ABPM in each case and BP taken by ABP device is shown in table 2. The mean casual BP was significantly higher than the blood pressure measured by the ambulatory BP device $(\mathrm{p} \leq 0.05)$.

\section{Nocturnal Dipping}

Mean nocturnal fall in SBP and DBP detected was $8.8 \mathrm{mmHg}$ and $7.9 \mathrm{mmHg}$ respectively (Table-3).The degree of nocturnal dipping was calculated from the fall in SBP and DBP, which ever was greater. The nocturnal dipping was 10$20 \%$ in $66 \%$ of cases, $5-10 \%$ in $28 \%$ cases and $<5$ $\%$ in $6 \%$ cases (Fig-1).None of the cases showed greater than $20 \%$ dipping.

Comparison of Mean ABPM Values and Nocturnal Dipping between Males and Females The mean daytime, nighttime and 24 hour BP in males and females are shown in Table -4. The difference is not statistically significant ( $p>0.05)$. Females had a significantly more nocturnal dip as compared to males. However statistically significant nocturnal dip between males and females was seen only for the diastolic BP $(\mathrm{p}<0.05)$.

\section{Comparison of Nocturnal Dipping in} Subjects $<40$ Years and $>40$ Years

There was a significantly higher dip for systolic BP in subjects aged $<40$ years $(p=0.005)$. We also compared the degree of nocturnal dipping between the two groups (Fig 2). Dipping was more frequent in subjects with age $<40$ years ( $\mathrm{p}=0.04)$.

\section{Problems Reported with ABPM}

Most of the cases tolerated the ABPM well. Few cases reported minor problems, which are listed in Table-5.

Table-1: Mean ambulatory blood pressure values

\begin{tabular}{|l|c|c|}
\hline BP measurment & $\begin{array}{c}\text { Systolic } \\
(\mathbf{m m H g} \pm \text { SD })\end{array}$ & $\begin{array}{c}\text { Diastolic } \\
(\mathbf{m m H g} \pm \text { SD })\end{array}$ \\
\hline Mean 24 hrs & $111.4 \pm 10.1$ & $71.5 \pm 9.65$ \\
\hline Mean daytime & $114.3 \pm 9.65$ & $74.5 \pm 9.04$ \\
\hline Mean nighttime & $105.5 \pm 11.44$ & $66.56 \pm 6.77$ \\
\hline ' $\mathrm{p}$ '* & $<0.001$ & $<0.001$ \\
\hline
\end{tabular}

*Between mean daytime and mean nighttime BP 
Table-2: Comparison of casual BP and mean 24 hour BP

\begin{tabular}{|l|c|c|c|c|}
\hline BP measurment & Casual BP & BP with ABPM & Mean difference & 'p' \\
\hline Systolic $(\mathrm{mmHg} \pm \mathrm{SD})$ & $119.26 \pm 8.71$ & $115.7 \pm 8.29$ & $4 \pm 3.35$ & 0.05 \\
\hline Diastolic $(\mathrm{mmHg} \pm \mathrm{SD})$ & $78.83 \pm 6.37$ & $75.17 \pm 7.92$ & $3.3 \pm 2.88$ & 0.02 \\
\hline
\end{tabular}

Table-3 Mean fall in nocturnal blood pressure (nocturnal dipping)

\begin{tabular}{|l|c|c|}
\hline & Systolic $(\mathbf{m m H g} \pm$ SD) & Diastolic $(\mathbf{m m H g} \pm$ SD) \\
\hline Difference in mean $(\mathrm{mmHg})$ & $-8.8 \pm 5.27$ & $-7.9 \pm 3.49$ \\
\hline
\end{tabular}

Table-4 Mean ambulatory blood pressure values and nocturnal dipping in males and females

\begin{tabular}{|l|c|c|c|c|}
\hline & BP measurment & Male & Female & "p' \\
\hline Systolic $(\mathrm{mmHg} \pm$ SD) & 24 hour & $110.36 \pm 11.33$ & $114.25 \pm 4.97$ & 0.102 \\
\cline { 2 - 5 } & Daytime & $113.54 \pm 10.9$ & $116.5 \pm 4.69$ & 0.155 \\
\cline { 2 - 5 } & Nighttime & $104.77 \pm 12.75$ & $107.5 \pm 6.94$ & 0.232 \\
\hline \multirow{3}{*}{ Diastolic $(\mathrm{mmHg} \pm$ SD) } & 24 hour & $69.95 \pm 7.59$ & $75.62 \pm 4.43$ & 0.009 \\
\cline { 2 - 5 } & Daytime & $72.95 \pm 8.24$ & $78.75 \pm 6.01$ & 0.025 \\
\cline { 2 - 5 } & Nighttime & $65.77 \pm 7.55$ & $68.87 \pm 3.44$ & 0.068 \\
\hline & Nocturnal dipping & Male & Female & \\
\hline Systolic $(\mathrm{mmHg} \pm$ SD) & Blood pressue dip & $-8.77 \pm 5.16$ & $-9.0 \pm 5.92$ & 0.459 \\
\hline Diastolic $(\mathrm{mmHg} \pm$ SD & Blood pressure dip & $-7.18 \pm 2.38$ & $-9.87 \pm 5.24$ & 0.03 \\
\hline
\end{tabular}

Table 5: Problems during ABPM

\begin{tabular}{|l|c|}
\hline Sideeffects & No of patients \\
\hline Disturbed sleep & $4(13 \%)$ \\
\hline Rash/Petechiae & 0 \\
\hline Pain in arm & $2(7 \%)$ \\
\hline Swelling of distalarm & 0 \\
\hline
\end{tabular}

Table 6: Comparison of mean ambulatory values of our study with the PAMELA study and study by Staessen and colleagues

\begin{tabular}{|l|c|c|c|c|}
\hline & BP measurment & Our study & PAMELA study & International database \\
\hline Systolic (mmHg \pm SD) & 24 hour & $111 \pm 10$ & $118 \pm 11$ & $116 \pm 10$ \\
\cline { 2 - 5 } & Daytime & $114 \pm 9$ & $123 \pm 11$ & $121 \pm 11$ \\
\cline { 2 - 5 } & Nighttime & $105 \pm 11$ & $108 \pm 16$ & $106 \pm 11$ \\
\hline \multirow{3}{*}{ Diastolic $(\mathrm{mmHg} \pm$ SD } & 24 hour & $71 \pm 7$ & $74 \pm 7$ & $70 \pm 7$ \\
\cline { 2 - 5 } & Daytime & $74 \pm 8$ & $79 \pm 8$ & $75 \pm 8$ \\
\cline { 2 - 5 } & Nighttime & $66 \pm 6$ & $65 \pm 7$ & $61 \pm 8$ \\
\hline
\end{tabular}

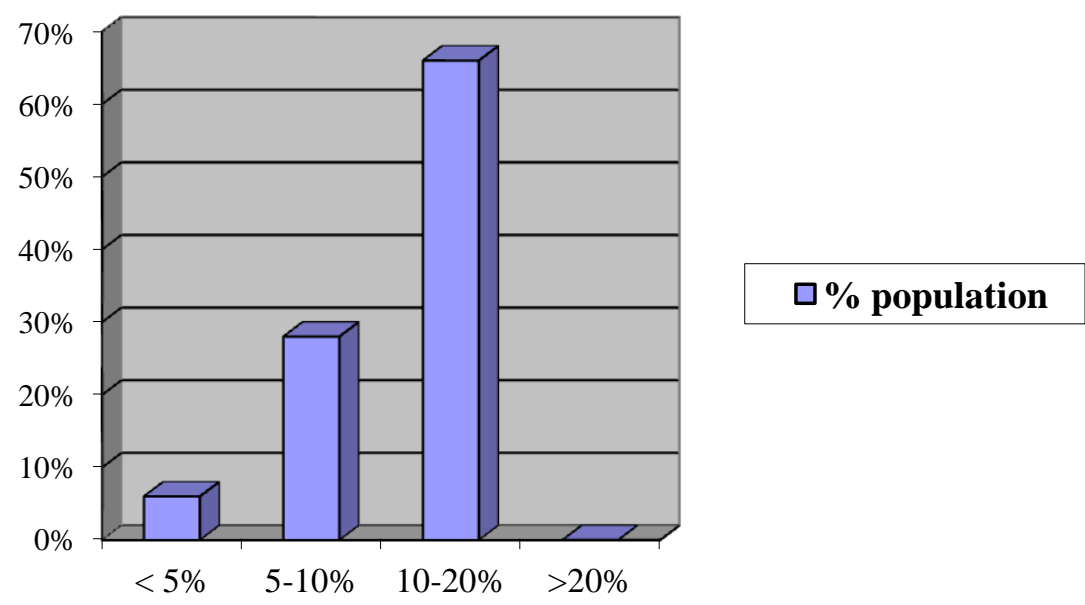

Fig 1: Degree of nocturnal dipping in the population 


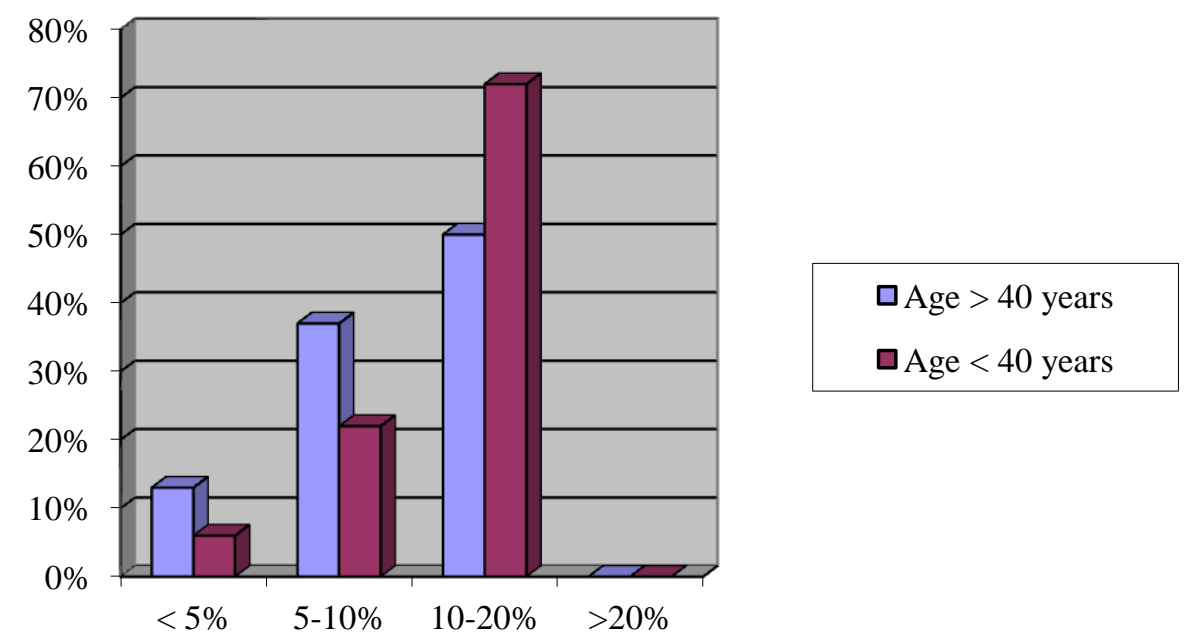

Figure 2: Degree of dipping in subjects $<40$ years and $>40$ years

\section{Discussion}

This is probably the first study in this region of Purvanchal of 24 hours ambulatory monitoring of BP. There have been several international studies $^{(2-4)}$, but the major ones are the PAMELA study $^{(2)}$ and the study by Staessen $\mathrm{J}$ et $\mathrm{a} 1^{(3)}$. Our findings and the findings in these two studies are compared in Table - 6. It can be seen that the findings obtained by us closely correlate with those reported in these studies. The upper $97.5 \%$ limit (mean $\pm \mathrm{SD}$ ) in our subjects was mean daytime BP 132/90, mean nighttime BP 126/78 and mean 24 hours BP 131/85 mm Hg. Population based outcome driven thresholds for normal ABP have been proposed as 130/85, 110/70 and 125/75 $\mathrm{mm} \mathrm{Hg}$ respectively for daytime, nighttime and 24 hours $\mathrm{ABP}^{(5)}$. A clinic $\mathrm{BP}$ of $140 / 90 \mathrm{~mm} \mathrm{Hg}$ corresponds to home BP values of $135 / 85 \mathrm{~mm} \mathrm{Hg}$ and to ABPM values defined as a daytime SBP/DBP of $135 / 85 \mathrm{~mm} \mathrm{Hg}$, a nighttime SBP/DBP of $120 / 70 \mathrm{~mm} \mathrm{Hg}$, and a 24-hour SBP/DBP of $130 / 80 \mathrm{~mm}^{(6)}$.

In our study the difference of BP between casual blood pressure and simultaneous ABP was 4/3.3 $\mathrm{mmHg}$ for systolic and diastolic respectively. This could be considered to be the white coat effect.

We have found nocturnal dipping of $5 \%-20 \%$ in $94 \%$ of our normotensive cases. In $6 \%$ the dipping was $<5 \%$ and in none of our subjects, the nocturnal dip was $>20 \%$. Nocturnal dipping is related to future vascular events ${ }^{(9-11)}$. Most investigators define nocturnal dippers as those where the nocturnal fall in BP is between $10 \%$ $20 \%$. However Staessen JA et.al ${ }^{(12)}$ found that with this criteria $18 \%$ to $30 \%$ of normotensives would be classified as non dippers. He recommended that a person should be considered as a dipper if there is any fall in nocturnal BP. Using this criterion he found that $3.2 \%$ of his cases were nondippers. Nocturnal dipping has also been reported to be less frequent in Asians ${ }^{(7)}$, but we did not observe this in the present study.

When the 24 hour, daytime and nighttime ABP values were compared in both males and females in our study, there was no significant difference in the average ABP values $(p>0.05)$. Comparing this data with international data, the Pamela study did not show any significant differences in the ABP values depending on sex. Manning et $\mathrm{al}^{(13)}$ reported in a study in normal British population that males had a smaller but significantly higher mean office and awake BP than females but there were no differences in asleep BP. Weinberg et $a 1^{(14)}$ showed that the diastolic ABP values were not different in the two sexes in a study on 352 normal Danish Subjects. However they found the systolic blood pressure as significantly 
higher in men than in women. Mancia et $\mathrm{al}^{(2)}$ found that the ABP measurements in women is somewhat less than that in men and ABP for both sexes increases less with aging than does office blood pressure.

Nocturnal dipping was more pronounced in females in our study as compared to males and the dipping in diastolic BP was found to be significantly greater in females $(p<0.05)$. Verdecchia et $\mathrm{al}^{(11)}$ in their study showed a greater nocturnal fall in BP in males. In our study nocturnal dipping of $>10 \%$ was present in $59 \%$ of males and $87.5 \%$ of females. This finding however needs to be confirmed by a large study.

When comparing the degree of nocturnal dipping $72 \%$ subjects were dippers and rest non-dippers for subjects aged <40 year. For subjects $>40$ years $50 \%$ subjects were dippers and 50\% subjects nondippers showing that non-dipping was more prevalent in subjects more than 40 years age. The lesser nocturnal dip in older population has been reported in various studies. In a Belgian population

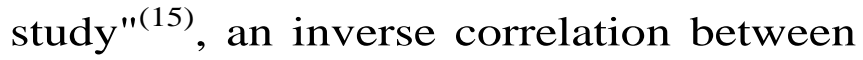
nocturnal fall in diastolic BP and age was seen. The partial regression coefficient adjusted for sex and body mass index, was compatible with a lesser nocturnal BP fall of $0.7 \mathrm{~mm} \mathrm{Hg}$ per decade of life. Similar observations for systolic and diastolic BP's have been reported in other European and Asian population. In general older people spend more time in bed than younger people, but they experience reduced slow-wave sleep, more nighttime wakefulness and increased fragmentation of sleep by awake periods.

The ambulatory BP monitoring was well tolerated by our cases and except for minor side effects no major problem occurred.

\section{Study Limitations}

The major limitation of our study was the size. There are large multicentre studies with data from European, Australian, and Asian populations. They are provided as a guide on normal ABPM values. The area of Purvanchal is different from other states in India being more backward and having more poverty. Use of ABPM in this population, its feasibility and normal values may add to the data that exists with ABPM values. A subsequent larger multicentre study may be undertaken to corroborate our findings.

\section{Summary and Conclusion}

The 24 hour BP profile in our cases was similar to the western population. The 24 hour recording of blood pressure provides better idea of blood pressure profile. It helps us to study the mean 24 hour blood pressure, nocturnal dipping, blood pressure load and the white coat effect. The latest guidelines have already incorporated ABPM in the diagnosis and management of hypertension.

\section{References}

1. Ernest ME, Bergus GR: Noninvasive 24 hour Ambulatory Blood Pressure Monitoring: Overview of Technology and Clinical Applications. Pharmacotherapy 2002; 22(5).597-612.

2. Mancia G, SegaR, Bravi $C$ et al: Ambulatory blood pressure normality: Results from the PAMELA Study. J. Hypertens 1995; 13:1377-1390.

3. Staessen JA, O'Brien ET, Atkins N, Amery AK. Ambulatory Blood pressure in normotensive compared with hypertensive subjects. J.Hypertens 1993; 11: 1289-1297.

4. Zhang W, Shi H, Wang R et at. Reference values of the ambulatory blood pressure: results from collaborative study. Chin J Cardiol.1995;10: 325-328.

5. Kikuya M, Hansen TW, Thijs L, et al. Diagnostic thresholds for ambulatory blood pressure monitoring based on 10-year cardiovascular risk. Circulation.2007; 
$115: 2145-52$.

6. Whelton etal.2017 ACC/AHA/AAPA/ABC /ACPM/AGS/APhA/ASH/ASPC/NMA/PC NA Guideline for the Prevention, Detection, Evaluation, and Management of High Blood Pressure in Adults. Journal of American College of Cardiology.2018; 71:e127.

7. Hyman DJ, Ogbonnaya K, Taylor AA, HoK. Pavli L VN. Ethnic differences in nocturnal blood pressure decline in treated hypertensives. AmIHypertens 2000; 13(8).854-91.

8. Brien EO, Beavers G, Lip GYH: Blood pressure measurement- Part III Automated sphygmomanometry: ambulatory blood pressure measurement. BMI 2001; 322.1110-14.

9. Ohkubo T. Imai Y, Tsuji I etaI : Relation between nocturnal decline in blood pressure and mortality. The Ohasama Study. Am J Hyper tens1997;10(11): 1201-7

10. Pierdomenico SD, Bucci A, Costantini F, Lapenna D, Cuccurullo F. Mezzetti A. Circadianblood pressure changes and myocardial lischaemia in hypertensive patients with coronary artery disease. J Am Coll Cardiol 1998; 31(7):1627-34.

11. Verdecchia P, Schillaci G, Borgioni C et al. Gender day night blood pressure changes, and left ventricular mass in essential hypertension. Dippers and peakers. Am J Hypertens 1995; 8(2):1936.

12. Staessen JA, Bieniaszewski L, O’Brien E et al. Nocturnal Blood pressure on Ambulatory Monitoring in a large International database the Ad - Hoc working group. Hypertension 1997; 29:30-9.

13. Manning G, Rushton L, Millar Craig MW. 24 hour ambulatory blood pressure; a sample from a normal British population. J Hum Hypertens. 1998;
12(2):123-7.

14. Weinberg N, Hoegholm A, Christensen HR et al. 24 hour ambulatory blood pressure in 352 normal Danish subjects related to age and gender. Am J Hypertens 1995; 8 (10 pt 1):986-87.

15. Staessen J, Bulpitt CJ, O'Brien E, Cox J et al. The diurnal blood pressure profile: a population study. Am J. Hypertens 1992; 5:386-392. 